\title{
Teoria dos prospectos: a tomada de decisão do investidor imobiliário à luz das finanças comportamentais
}

\section{Theory of prospects: the decision making of the real estate investor in the light of behavioral finance}

\author{
Anderson Dias Brito Graduado em Administração, Universidade Estadual do Sudoeste da Bahia (UESB), \\ Brasil - andersonbrito.adm@gmail.com \\ Marcelo Santos Amaral Doutor em Administração, Universidade Estadual do Sudoeste da Bahia (UESB), Brasil - \\ amaral69@gmail.com
}

\section{RESUMO}

A maioria dos investidores possui determinado nível de aversão aos riscos, portanto é recomendado que seja analisado seu processo decisório. O presente estudo tem como objetivo, ao replicar o estudo clássico sobre Finanças Comportamentais, através da metodologia proposta por Tversky e Kahneman (1979), compreender como investidores imobiliários que atuam com locação de imóveis tomam decisões. Trata-se de uma pesquisa quantitativa descritiva que utilizou como método de coleta de dados o questionário estruturado. Os questionários foram aplicados em 85 investidores imobiliários da cidade de Vitória da Conquista - BA. Os resultados demostram que estes investidores tomam decisões diferentes quando o mesmo problema é reformulado. Tal comportamento se dá pela presença dos efeitos certeza, reflexão e isolamento. Estes efeitos podem influenciar o processo decisório dos investidores levando-os a erros cognitivos e tornando as decisões enviesadas e inconsistentes.

Palavras-chave: Processo Decisório. Finanças Comportamentais. Racionalidade Limitada.

\begin{abstract}
Most investors have a certain degree of risk aversion, so it is recommended that their decision-making process be reviewed. The objective of this study is to replicate the classic Behavioral Finance study through the methodology proposed by Tversky and Kahneman (1979) in order to understand how real estate investors that rent real estate make decisions. It is a descriptive quantitative research that used the structured questionnaire as a method of data collection. The questionnaires were applied to 85 real estate investors in the city of Vitória da Conquista - BA. The results show that these investors make different decisions when the same problem is reformulated. Such behavior is due to the presence of effects of certainty, reflection and isolation. These effects may influence the decision-making process of investors leading to cognitive errors and making biased and inconsistent decisions.
\end{abstract}

Keywords: Decisional process. Behavioral Finance. Limited Rationale. 


\section{INTRODUÇÃO}

A rotina de um investidor é baseada em tomar decisões. Essas decisões podem estar fundamentadas em um conjunto de pressupostos para o alcance de seu objetivo financeiro. Na gestão organizacional, a tomada de decisão é um processo fundamental e complexo, e este processo sofre interferência em situações de imprevisibilidade e de limitações racionais. Tais interferências impactam no desempenho organizacional (FAGUNDES; SCHNORREMBERGER; LUNKES, 2018).

As bases das teorias de finanças estão na microeconomia clássica (finanças tradicionais) e têm sofrido modificações com a Hipótese do Mercados Eficientes - HME e a Teoria da Utilidade Esperada - TUE (OLIVEIRA KRAUTER, 2015). A HME e a TUE se mostraram insuficientes para explicar o comportamento do investidor. As Finanças Comportamentais apresentam condições de preencher algumas das lacunas deixadas pelas HME e TUE a respeito dos fenômenos inseridos no processo decisório.

Os aspectos irracionais também podem influenciar o processo decisório. O investidor, ao lidar com diferentes situações que envolvam a probabilidade de ganhos ou perdas, pode tomar decisões com base em aspectos irracionais e emocionais. Finanças Comportamentais são um novo campo de investigação que busca compreender estes aspectos do processo decisório. Bilk et al. (2018) definem as Finanças Comportamentais como um segmento interdisciplinar das finanças, que busca conceitos da economia, do mercado, da gestão e da psicologia para explicar os vieses cognitivos que podem influenciar o investidor no processo decisório.

Tversky e Kahneman (1979), ao refutarem o modelo de racionalidade econômica vigente à época, formularam a Teoria da Perspectiva ou Teoria do Prospecto. No campo das Finanças Comportamentais, mais precisamente na Teoria do Prospecto, as decisões dos investidores dependem muito da forma como eles enxergam o problema naquele momento. Diferentes investidores podem reagir de maneiras distintas ao mesmo problema quando a forma de apresentação desse problema é alterada (MARTINS; LIMA; SILVA , 2015).

As contribuições de Tversky e Kahneman (1979) foram discutidas e aprofundadas por outros autores (YOSHINAGA; RAMALHO, 2014; BARROS; FELIPE, 2015; ROSA; MILANI, 2015; OLIVEIRA; KRAUTER, 2015; FERNANDES et al., 2016). Tais autores ajudaram a criar um arcabouço teórico e permitiram avanços nos estudos do comportamento em situações que envolvem tomada de decisão e risco.

A compreensão dos fatores cognitivos envolvidos no processo de decisão dos investidores pode ajudar a elucidar os comportamentos do mercado. $\mathrm{O}$ crescimento das experiências e pesquisas nessa área buscam contribuir para o aperfeiçoamento e criação de novos métodos financeiros, em substituição aos modelos financeiros tradicionais (FERNANDES et al., 2016).

A maioria das pesquisas sobre a Teoria do Prospecto à luz das contribuições de Tversky e Kahneman (1979) possui a amostra composta por acadêmicos de diferentes níveis. Alguns exemplos são Barros e Felipe (2015), Rosa e Milani (2015), Oliveira e Krauter (2015), Fernandes et al. (2016) e Bilk et al. (2018). Há poucos estudos com a amostra composta por investidores, e o ineditismo deste estudo se evidencia na produção de dados empíricos com investidores que adquiriram imóveis para fins de locação.

O objetivo deste artigo foi, ao replicar o estudo clássico sobre Finanças Comportamentais, através da metodologia proposta por Tversky e Kahneman (1979), compreender como investidores que atuam com locação de imóveis na cidade de Vitória da Conquista - BA tomam decisões. Dessa forma, o presente estudo se desdobra em cinco seç̧ões: a primeira, introdutória; a segunda seção traz o referencial teórico para fundamentar as discussões; a terceira seção trata do percurso metodológico que explicita o tipo de estudo, o objetivo, os instrumentos de coleta e tratamento destes; a quarta seção apresenta os resultados desta pesquisa e, a quinta a seção trata das considerações finais em que realça a aplicação do conteúdo desenvolvido. 


\section{REFERENCIAL TEÓRICO}

Há atualmente teorias utilizadas para compreender a complexidade dos fenômenos que cercam o comportamento do investidor, sendo as principais: Teoria da Utilidade Esperada (TUE), Hipótese de Mercados Eficientes (HME) e, por fim, as Finanças Comportamentais.

\subsection{Teoria da Utilidade Esperada}

Uma das teorias que alcançou destaque foi a da Teoria da Utilidade Esperada, que nasceu do trabalho Theory of games and economic behavioral- Teoria dos jogos e comportamento econômico, em tradução livre, de 1944, de autoria de John Von Neumann e Oskar Morgenstern (MACEDO et al., 2007). Essa teoria aponta a necessidade da matemática e do conhecimento estatístico para fundamentar uma decisão em modelos econômicos e maximizar a utilidade total (FRIES, 2017).

Para Baldo (2007, p. 13), "durante muito tempo, os economistas tratavam a utilidade [econômica] como um indicador de satisfação de uma pessoa". Essa utilidade era difícil de ser calculada e interpretada diante da complexidade do processo de decisão, ora levando a acertos neste cálculo, ora levando a erros de previsões. Os agentes econômicos eram considerados agentes econômicos racionais que, ao investirem, analisavam de forma objetiva as informações disponíveis, porém não conseguiam prever o comportamento do mercado.

Silva Filho (2011), ao avaliar a Moderna Teoria de Finanças com base na Teoria Econômica Neoclássica, considera o mundo formado por agentes capazes de tomar decisões com racionalidade ilimitada, em conjunto com a Teoria da Utilidade Esperada. Para o autor, as pessoas preferem não se arriscar quando o resultado possível visualizado é um ganho, preferindo diminuir a probabilidade de perda do que aumentar a probabilidade de ganho. Desse modo, a racionalidade dos agentes econômicos busca maximizar a utilidade e diminuir os riscos ou até eliminá-lo, de modo a influenciar o comportamento humano e, consequentemente, suas decisões.

Para o modelo racional, em situações de incerteza, os sujeitos racionais processam as informações de forma objetiva e baseada em um conjunto definido de preferências (MACEDO et al., 2007). Os erros cometidos são aleatórios e não são provenientes de uma análise otimista ou pessimista. O modelo racional exclui a hipótese que o mercado opera com características irracionais.

\subsection{Hipótese dos Mercados Eficientes}

A Hipótese de Mercados Eficientes (HME) trouxe grandes contribuições ao mercado financeiro, como por exemplo, contribuiu para fundamentar diversos modelos de precificação de ativos. Seus primeiros estudos iniciaram na década de 40, ao mostrar a eficiência do mercado quando os investidores ganhavam mais com a estratégia de comprar e manter ativos do que com operações financeiras (OLIVEIRA; KRAUTER, 2015).

Eugene Fama, em 1970, foi quem trouxe importantes contribuições sólidas para as discussões que envolvem a HME. O autor afirma que a eficiência do mercado financeiro, em relação ao preço dos ativos, é consequência das informações disponíveis sobre eles. Do mesmo modo, a HME pressupõe que as flutuações não podem são previstas, mas, quando similares, podem ser avaliadas matematicamente (OLIVEIRA; KRAUTER, 2015).

A classificação da HME é baseada em três diferentes níveis de eficiências: fraca, semiforte e forte (FAMA, 1970). Para o autor, a eficiência em nível fraco expõe que as informações podem se limitar ao conhecimento dos preços anteriores dos ativos; a eficiência em nível semiforte considera que os preços são um resultado de todas as informações disponíveis aos investidores e que estes preços se alteram à medida em que surgem novas informações; a eficiência em nível forte remete à ideia de que todas as informações são públicas, não existindo um monopólio ou grupos privilegiados. 
De acordo com Shleifer (2000), a HME afirma que a avaliação dos ativos é racional, e mesmo que investidores irracionais participem das transações, cria-se um equilíbrio que não interfere nos preços dos ativos. Assim, o mercado eficiente é um local onde existem diversos investidores racionais, maximizadores de lucros e que competem entre si, de modo a tentar prever os valores futuros dos ativos, levando em consideração que as informações são disponíveis igualitariamente (MACEDO et al., 2007)

Para Shleifer (2000) e Macedo et al. (2007), diante das implicações da teoria da HME, os investidores não devem ter a expectativa de superar o mercado, ou seja, ter um desempenho acima do mercado, pois os esforços e instrumentos utilizados para a analisar, avaliar e escolher os ativos são desperdícios. Devido à complexidade e às informações disponíveis que surgem a todo instante, não existe uma regra que permita a previsão dos preços dos ativos.

\subsection{Finanças Comportamentais}

As Finanças Comportamentais estão conseguindo cada vez mais espaço nos debates e pesquisas acadêmicos. Apesar dos estudos nesta área serem relativamente novos, existem contribuições nacionais e internacionais voltadas para a compreensão das decisões irracionais. Os estudos das Finanças Comportamentais surgiram na tentativa de mesclar os estudos financeiros tradicionais com os estudos do comportamento humano para o processo decisório, partindo do pressuposto que os agentes econômicos são suscetíveis a erros sistemáticos e ações irracionais.

O nível de educação dos investidores não resulta necessariamente em uma tomada de decisão racional ou irracional. Oliveira e Krauter (2015) afirmam que as pessoas qualificadas na área de negócios e com experiência profissional também tomam decisões irracionais. Nessesentido aqueles dotados de conhecimento na área também estão propensos à irracionalidade, uma vez que são dotados de uma racionalidade limitada inerente ao ser humano como um todo.

As Finanças Comportamentais adotam como premissa que tomadores de decisão não se comportam de forma estritamente racional, realizando julgamentos e promovendo escolhas sob a influência de aspectos emocionais (YOSHINAGA; RAMALHO, 2014). Em outras palavras, as Finanças Comportamentais levam em consideração não apenas o viés racional, mas também as emoções dos indivíduos que interferem na tomada de decisão.

\subsection{Teoria da Perspectiva (Prospecto)}

A teoria da perspectiva apresenta uma alternativa a TUE, ao introduzir a função de distorção da probabilidade observada em função do valor que expressa a variação de riqueza (LOBEL; KLOTZLE; SILVA, 2017). Através do uso da Teoria dos Prospectos, é possível compreender de maneira eficiente os vieses que interferem no processo decisório. Estes vieses levam ou podem levar a erros de preferências, e são identificados como os principais fatores que interferem na tomada de decisão (FERNANDES, et al., 2016)

Partindo do pressuposto que a tomada de decisão não é um processo puramente racional, a Teoria da Perspectiva leva em consideração que as emoções podem interferir na tomada de decisão, bem como prejudicar a interpretação do contexto em que se está inserido. Assim, o ponto principal dessa teoria é a descrição de como os indivíduos escolhem por alternativas através de maneiras ilógicas por diversos motivos. A Teoria do Prospecto analisa os comportamentos dos investidores a partir de seus efeitos no processo de tomada de decisão, sendo os principais, certeza, reflexão e isolamento.

No trabalho seminal de Tversky e Kahneman (1979) foi descrito o efeito certeza, em que os indivíduos atribuem uma importância muito superior aos resultados garantidos do que os prováveis. Yoshinaga e Ramalho (2014) identificaram a existência de preferências dos pesquisados por opções que ofereceram ganhos certos, mas que apresentaram inconsistências quando envolveram perspectivas com baixíssimas probabilidades. Nesse sentido, o efeito certeza vai de encontro aos princípios da TUE, uma vez que se leva em consideração fatores comportamentais e não somente dados exatos para a tomada de decisão. 
Em relação ao efeito reflexão, Martins, Lima e Silva (2015) afirmam que as pessoas tendem a ser avessas ao risco quando lidam com problemas com resultados esperados de ganhos (positivos), ao mesmo tempo em que são propensas ao risco em situações que envolvam perdas (negativos). Bilk et al. (2018, p. 31) defendem que "[...] o efeito reflexo detém a assimetrias da aversão ao risco em ganhos para arriscar procurando em perdas, o objetivo se torna mais íngreme para perdas do que ganhos quanto a aversão às perdas". Dessa forma, o efeito reflexão também segue em direção oposta à TUE, tendo em vista que, ao deslocar os resultados de ganhos para perdas, os sujeitos são mais propensos a assumir risco, isto é, eles se tornam avessos a perdas e não aos riscos.

Quanto ao efeito isolamento, as pessoas tendem a simplificar suas escolhas através do desmembramento do conjunto de informações, pois é mais fácil focar em um componente da informação de cada vez (OLIVEIRA; KRAUTER, 2015). O efeito isolamento mostra que os indivíduos separam e excluem características que envolvem as probabilidades e concentram suas análises sobre os componentes que distinguem as opções de escolha (BARROS; FELIPE, 2015). Assim, os agentes têm dificuldades em analisar todas as probabilidades e buscam a simplificação, porém este método de isolamento das variáveis envolvidas no processo decisório pode levar à falsa interpretação do contexto.

O efeito isolamento é citado por Tversky e Kahneman (1979) como o processo pelo qual as pessoas, muitas vezes, fracionam uma informação, desconsiderando alguns componentes compartilhados e se concentrando nos componentes que os distinguem. As escolhas são conduzidas pela maneira em que estão representadas na situação. A maneira que a situação está expressa e a análise simplificada desta situação pode levar a erros sistemáticos.

Portanto, os agentes econômicos são dotados de emoções que contribuem para a tomada de decisão, uma vez que possuem aspectos subjetivos que podem dificultar a compreensão do contexto no qual estão inseridos. A tomada de decisão dos investidores pode ser compreendida através de seus efeitos certeza, reflexão e isolamento: quanto ao primeiro, os sujeitos buscam por ganhos, mas evitam os riscos de perder ou não ganhar nada; em caso de perdas, se existirem riscos de evitá-las, eles se tornam adeptos a estes riscos, que é o efeito reflexão; e quanto ao isolamento, os indivíduos tendem a desconsiderar elementos similares e destacar elementos diferentes na tomada de decisão.

\section{PROCEDIMENTOS METODOLÓGICOS}

O objetivo deste artigo foi, ao replicar o estudo clássico sobre Finanças Comportamentais com a metodologia proposta por Tversky e Kahneman (1979), compreender como investidores que atuam com locação de imóveis na cidade de Vitória da Conquista tomam decisões. Optou-se por uma pesquisa quantitativa descritiva: quantitativa, devido a análise da relação causa-efeito entre os fenômenos, o que significa traduzir em números opiniões e informações para classificá-las e analisá-las (PRODANOV; FREITAS, 2013); e descritiva, porque retrata os fenômenos investigados, possibilitando conhecer os problemas vivenciados (TRIVIÑOS, 2009).

A população deste estudo é composta por 85 investidores imobiliários que atuam com locação de imóveis na cidade de Vitória da Conquista - BA. A amostra foi estabelecida aleatoriamente e de maneira não probabilística, levando-se em consideração a facilidade de acesso dos investidores, bem como o interesse em contribuir. Dessa forma, foi entregue o formulário aos investidores ou encaminhado por meios eletrônicos, entre 07 e 27 de março de 2019.

O formulário desta pesquisa foi resultado de uma adaptação dos métodos utilizados por Tversky e Kahneman (1979). Os autores apresentaram circunstâncias hipotéticas aos respondentes, que eram convidados a imaginar que teriam de lidar com situações que envolvam probabilidades de ganhos ou perdas. As adaptações do referido questionário envolveram a tradução do idioma e a utilização da moeda brasileira.

Em relação a validade do formulário, Tversky e Kahneman (1979), ao defenderem sua própria metodologia, afirmaram que: a) a dependência por escolhas hipotéticas não permite a generalização dos resultados. b) todos os outros métodos utilizados para mensurar o utilitarismo sofrem grandes inconvenientes. c) estudos de campos com situações reais apenas fornecem resultados brutos, uma vez que as probabilidades 
e utilidades não podem ser devidamente medidas. d) o uso dos métodos baseia-se nos pressupostos de que as pessoas geralmente sabem como se comportaria em situações reais. e) os respondentes não têm razão especial para disfarçar suas verdadeiras preferências.

O procedimento de análise foi quantitativo, em que os dados, após serem coletados, foram categorizados, tabulados e analisados com o software Statistical Package for the Social Sciences - SPSS, em conjunto com o Microsoft Excel 2016.

\section{ANÁLISE DOS RESULTADOS}

Este capítulo apresenta a análise dos dados e discussões.

\subsection{Efeito Certeza}

No problema 01 (tabela 01), a opção "A" apresenta 99\% de ganhar no mínimo de R\$: 2.400,00, sendo $33 \%$ de ganhar $\mathrm{R} \$ 2.500,00$. A maioria dos respondentes optou pela alternativa que ofereceu certeza de ganho, mas com retorno de $\mathrm{R} \$ 2.400,00$ (Opção “B”). A partir deste resultado, levantam-se duas hipóteses. A primeira que os respondentes utilizaram um atalho mental para a tomada de decisão, não levando em consideração o somatório de 99\%. A segunda hipótese, defendida por Tversky e Kahneman (1979), é que os respondentes foram atraídos pelo efeito certeza, levando-os à aversão aos riscos, mesmo ao nível de $1 \%$.

Tabela 01 - Problemas 01 e 02

\begin{tabular}{|c|c|c|c|}
\hline Problema & Opção & Prospecto & Pesquisados \\
\hline \multirow[t]{2}{*}{01} & $A$ & $\begin{array}{l}33 \% \text { de chance de ganhar } \mathrm{R} \$ 2.500 ; 66 \% \text { de chance de ganhar } \mathrm{R} \$ \\
2.400 ; 1 \% \text { de chance de ganhar } \mathrm{R} \$ 0\end{array}$ & $26,51 \%$ \\
\hline & B & $100 \%$ de chance de ganhar $\mathrm{R} \$ 2.400$ & $73,49 \%$ \\
\hline \multirow{3}{*}{02} & $A$ & $\begin{array}{l}33 \% \text { de chance de ganhar } \mathrm{R} \$ 2.500 ; 67 \% \text { de chance de ganhar } \mathrm{R} \$ \\
0\end{array}$ & $43,37 \%$ \\
\hline & & & \\
\hline & $\mathrm{B}$ & $\begin{array}{l}34 \% \text { de chance de ganhar } \mathrm{R} \$ 2.400 ; 66 \% \text { de chance de ganhar } \mathrm{R} \$ \\
0\end{array}$ & $56,63 \%$ \\
\hline
\end{tabular}

Fonte: Dados da pesquisa (2019).

No problema 02 (tabela 01), a maioria dos respondentes optou pela opção "B". Tal alternativa possui maior probabilidade de ganho, mesmo com um valor menor, ou seja, foram avessos aos riscos. É possível observar que uma porcentagem significativa (43,37\%) dos indivíduos optou pela opção "A". Essa alternativa está um ponto percentual abaixo da opção "B", mas oferece $R \$ 100,00$ de ganho incremental. Em outras palavras, uma parcela dos respondentes preferiu um risco maior, mas também um maior retorno.

Para os respondentes, investir em imóveis para alugar possui seus riscos, porém o nível de risco é considerado baixo e até aceitável. Com isso, o investidor apresenta características conservadoras em situações de risco e busca por opções que oferecem maior probabilidade de ganho, mesmo sendo um valor menor.

Ao relacionar os resultados do problema 01 com estes do problema 02, a maioria dos respondentes optou pela mesma opção "B". Em ambos os problemas foi constatada a preferência por alternativas que oferecem ganhos certos ou que mais oferecem probabilidades de ganho, não caracterizando propriamente um desvio no processo decisório. No entanto, aqueles que optaram por opção diferentes (ser avesso ao risco em uma questão e aceitá-lo para conseguir um retorno maior, em outra) apresentam um paradoxo no processo decisório e que os levou a erros cognitivos. Portanto, esse paradoxo sugere que as preferências não dependem somente da utilidade disposta nos resultados em si, mas também na probabilidade destes 
resultados (KIMURA; BASSO, 2003) e na forma como os respondentes entendem os riscos e retornos envolvidos.

O problema 03 (tabela 02) também avalia o efeito certeza no processo decisório. De acordo com esse efeito, espera-se que os respondentes prefiram a opção " $B$ ", ao invés da " $A$ ", o que de fato acontece, pois os respondentes optaram em sua maioria por perspectivas que envolvem certezas de ganhos.

Tabela 02 - Problemas 03 e 04

\begin{tabular}{cccc}
\hline Problema & Opção & Prospecto & Pesquisados \\
\hline 3 & A & $80 \%$ de chance de ganhar R\$ 4.000; $20 \%$ de chance de ganhar $\mathrm{R} \$ 0$ & $18,80 \%$ \\
& B & $100 \%$ de chance de ganhar $\mathrm{R} \$ 3.000$ & $81,20 \%$ \\
\hline 4 & A & $20 \%$ de chance de ganhar $\mathrm{R} \$ 4.000 ; 80 \%$ de chance de ganhar $\mathrm{R} \$ 0$ & $16,50 \%$ \\
& B & $25 \%$ de chance de ganhar $\mathrm{R} \$ 3.000 ; 75 \%$ de chance de ganhar $\mathrm{R} \$ 0$ & $83,50 \%$
\end{tabular}

Fonte: pesquisa de campo (2019).

No problema 04 (tabela 02), houve preferência pela opção "B". Tais resultados apresentam aversão ao risco, pois apesar do problema não ter a opção de 100\% de ganho, os respondentes escolheram a alternativa que tinha maior probabilidade de ganho, mesmo com um retorno menor.

A partir da comparação do problema 03 com o problema 04, percebe-se que os respondentes escolherem a mesma opção nos dois problemas. Tais alternativas escolhidas mostram um comportamento avesso aos riscos, optando por um ganho certo, mas com um valor menor e aceitando a perda, porém também com um valor menor. No problema 05 (tabela 03), segundo o efeito certeza, haverá predileção pela opção "B", tendo em vista que oferece $100 \%$ de ganho, mesmo com um retorno menor. O problema 05 confirma o efeito certeza, pois os respondentes optaram pela alternativa que ofereceu $100 \%$ de ganho. Em termos de utilidade: $0,50 \times U$ (viagem de 3 semanas) $<1,00 \times U$ (viagem de 1 semana).

Tabela 03 - Problemas 05 e 06

\begin{tabular}{cccc} 
Problema & Opção & Prospecto & Pesquisados \\
\hline 5 & A & $\begin{array}{l}50 \% \text { de chance de ganhar uma viagem de três semanas para a } \\
\text { Inglaterra, França e Itália; } 50 \% \text { de chance de não ganhar nada. }\end{array}$ & $18,82 \%$ \\
& & $\begin{array}{l}100 \% \text { de chance de ganhar uma viagem de uma semana para a } \\
\text { Inglaterra }\end{array}$ & $81,18 \%$ \\
6 & A & $\begin{array}{l}5 \% \text { de chance de ganhar uma viagem de três semanas para a } \\
\text { Inglaterra, França e Itália; } 95 \% \text { de chance de não ganhar nada }\end{array}$ & $37,65 \%$ \\
& & $\begin{array}{l}10 \% \text { de chance de ganhar uma viagem de uma semana para a } \\
\text { Inglaterra; } 90 \% \text { de chance de não ganhar nada }\end{array}$ & $62,35 \%$
\end{tabular}

Fonte: pesquisa de campo (2019).

No problema 06 (tabela 03), houve aversão aos riscos. Mesmo em situações de baixa probabilidade, os respondentes preferiram a alternativa que ofereceu maior possibilidade de ocorrência do cenário positivo, mesmo que esse cenário apresente retorno menor. Outro ponto que merece destaque é o nível de preferência pela opção "A": apesar dos respondentes que escolheram essa alternativa não terem sido maioria, uma parcela significativa $(37,65 \%)$ optou pela alternativa de maior retorno e menor probabilidade de ganho. 
Na relação do problema 05 e 06, houve preferência em ambos os problemas pela opção "B", o que indica a predileção por um ganho mais certo, se comparado com a outra alternativa. Novamente, os investidores imobiliários se mostraram avessos aos riscos.

Para o problema 07 (tabela 04), os respondentes foram avessos aos riscos ao escolher a opção "B", a qual oferece maior probabilidade de ganho, mesmo com o valor a ganhar $50 \%$ menor, se comparado a opção "A".

Tabela 04 - Problemas 07 e 08

\begin{tabular}{cccc}
\hline Problema & Opção & Prospecto & Pesquisados \\
\hline 7 & A & $45 \%$ de chance de ganhar R\$ 6.000; 55\% de chance de ganhar R\$ 0 & $16,50 \%$ \\
& B & $90 \%$ de chance de ganhar R\$ 3.000 10\% de chance de ganhar $\mathrm{R} \$ 0$ & $83,50 \%$ \\
\hline 8 & A & $0,1 \%$ de chance de ganhar $\mathrm{R} \$ 6.000 ; 99,9 \%$ de chance de ganhar $\mathrm{R} \$ 0$ & $57,83 \%$ \\
& B & $0,2 \%$ de chance de ganhar $\mathrm{R} \$ 3.000 ; 99,8 \%$ de chance de ganhar $\mathrm{R} \$ 0$ & $42,17 \%$
\end{tabular}

Fonte: pesquisa de campo (2019).

No problema 08 (tabela 04), os respondentes preferiram a opção " $\mathrm{A}$ ", não sendo avessos aos riscos e buscando um retorno maior. Percebe-se que as probabilidades são baixíssimas $(0,1 \%$ e $0,2 \%)$ e em tais situações, a maiorias dos respondentes optaram pelo maior ganho e não pela maior probabilidade de ganho. Dessa forma, suas escolhas apresentaram desvios em relação a TUE. Ainda assim, 42,17\% dos respondentes desta pesquisa optaram pela opção de maior probabilidade de ganho, corroborando o perfil conservador do investidor imobiliário mesmo em situações de baixa probabilidade e de retorno menor.

A partir da relação do problema 07 com o problema 08, os respondentes optaram por alternativas diferentes entre os problemas, sendo " $B$ " e " $A$ ", respectivamente. Enquanto o problema 07, houve a aversão ao risco, no problema 08, o mesmo efeito não foi constatado. Assim, identifica-se um desvio na TUE, bem como uma inconsistência no processo decisório dos respondentes.

\subsection{Efeito Reflexão}

No problema 09 (tabela 05), a maioria dos respondentes optou pela opção "A", a qual oferece $20 \%$ de chance de evitar a perda completamente, mas também oferece $80 \%$ de chance de perder uma quantia maior que a da opção "B". Assim, os indivíduos tiveram um comportamento avesso à perda e não aos riscos, caracterizando assim, o efeito reflexão. O efeito reflexão faz com que ao deslocar os resultados de ganhos para perdas, os sujeitos são mais propensos a assumir risco. É possível observar um percentual de $27,85 \%$ dos indivíduos de preferiram a opção "B", apesar de não ser maioria, é um percentual relevante, pois mostra a presença de indivíduos que foram avessos aos riscos e assumiram a certeza de uma perda, porém com um valor menor.

Tabela 05 - Problemas 09 e 10

\begin{tabular}{cccc}
\hline Problema & Opção & Prospecto & Pesquisados \\
\hline 9 & A & $80 \%$ de chance de perder R\$ 4.000; 20\% de chance de perder R\$ 0 & $72,15 \%$ \\
& B & $100 \%$ de chance de perder 3.000 & $27,85 \%$ \\
\hline 10 & A & $20 \%$ de chance de perder R\$ 4.000; 80\% de chance de perder R\$ 0 & $31,76 \%$ \\
& B & $25 \%$ de chance de perder R\$ 3.000; 75\% de chance de perder R\$ 0 & $61,18 \%$ \\
\hline
\end{tabular}

Fonte: pesquisa de campo (2019). 
O problema 10 (tabela 05) oferece situações com baixas probabilidades de perda e altas probabilidades de evitar essa perda. Os respondentes, dessa vez, buscaram a opção "B", a qual possui maior probabilidade de perda, mas com valor menor. A equação da utilidade no presente estudo é $0,2 \times U(-4000)<$ $0,25 \times$ U (3000).

Na relação do problema 09 com o problema 10, a maioria dos respondentes escolheram alternativas distintas, sendo " $A$ " $\mathrm{e}$ "B", respectivamente. Enquanto no problema 09, os indivíduos optaram pela alternativa que ofereceu possibilidade de evitar a perda, mas com probabilidade de perder um valor ainda maior, no problema 10, os respondentes escolheram a alternativa que ofereceu maior probabilidade de perda, mas com um valor menor. Tais resultados mostram uma inconsistência no processo decisório dos respondentes.

O problema 09 é semelhante ao problema 03, a diferença é que o primeiro problema oferece um cenário positivo e neutro ( $X \%$ de ganhar $Y ; X \%$ de ganhar $\$ 0$ ) e o segundo problema oferece um cenário negativo e neutro ( $X \%$ de perder $Y ; X \%$ de perder $\$ 0$ ). De acordo com o quadro 01, 59,5\% dos respondentes escolheram alternativas diferentes ao deslocar a situação de ganho para perda. Na situação positiva, os respondentes optaram pela certeza de ganho, indo de acordo com o efeito certeza, sendo avessos aos riscos. Na situação negativa, os respondentes foram adeptos aos riscos para evitarem a perda.

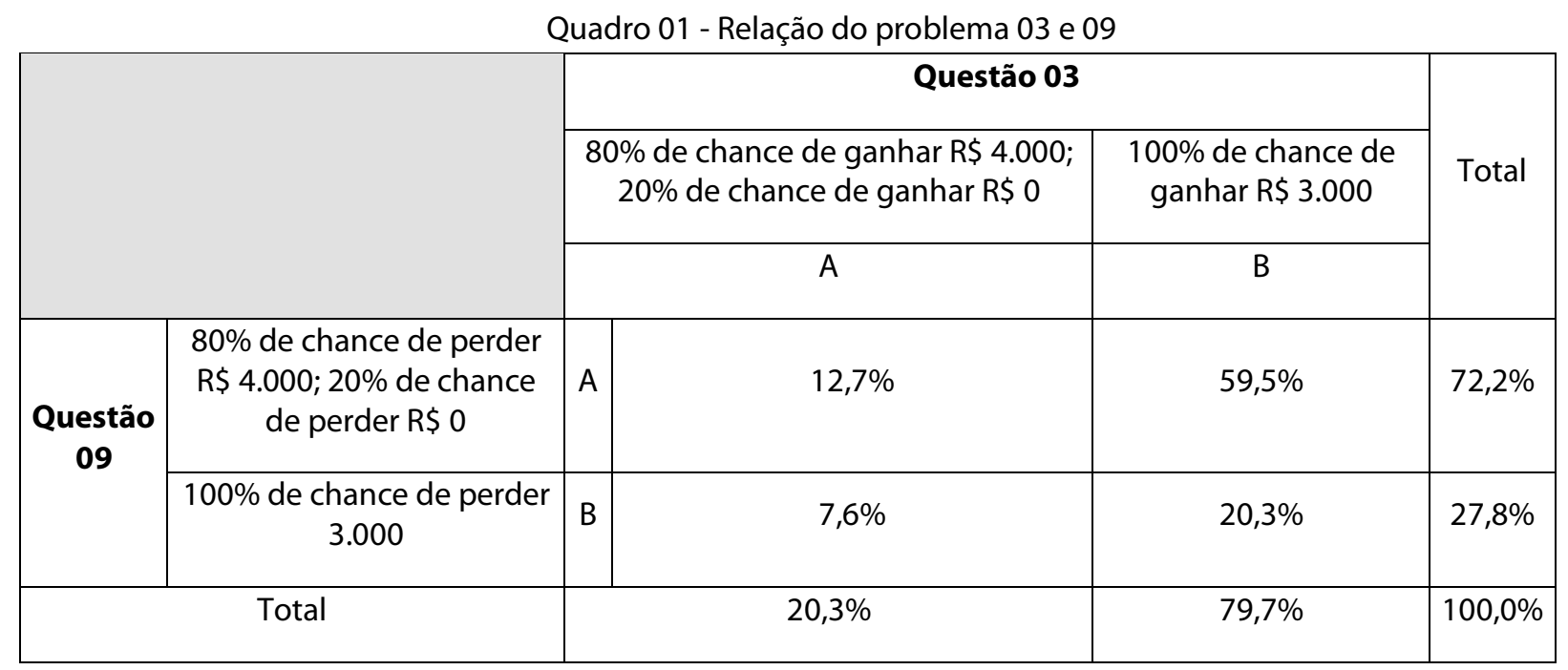

Fonte: pesquisa de campo (2019).

O problema 10 é semelhante ao problema 04, alterando apenas o efeito positivo/negativo (ganho ou perda). De acordo com o quadro $02,55,7 \%$ dos indivíduos escolheram a opção "B" em ambos os problemas. No cenário positivo (problema 04), os respondentes optaram pela que ofereceu maior probabilidade de ganho, mas com valor menor. No cenário negativo (problema 10), os indivíduos optaram pela opção que ofereceu a maior probabilidade de perda, mas também com um valor menor. Nesta comparação, os indivíduos optaram por ganhar menos ou perder menos, do que não ganhar nada ou perder mais, descartando assim, o efeito reflexão.

No problema 11 (tabela 06), os respondentes apresentaram preferências pouco concisas entre as opções " $A$ " e "B". Uma parcela dos respondentes foi avessa às perdas e não aos riscos (opção " $A$ "). Tal alternativa oferece probabilidades médias de não perder dinheiro, mas também há probabilidades também médias de perder o dobro da opção "B". Por outro lado, também existe uma parcela dos respondentes que preferiram a alternativa " $B$ ", ou seja, foram avessos aos riscos e não as perdas, uma vez que preferiram maior probabilidade de perda, mas com um valor menor. 
Quadro 02 - Relação do problema 04 e 10

\begin{tabular}{|c|c|c|c|c|c|}
\hline & & & Pro & lema 04 & \\
\hline & & & $\begin{array}{c}20 \% \text { de chance de } \\
\text { ganhar } \mathrm{R} \$ 4.000 ; 80 \% \text { de } \\
\text { chance de ganhar } \mathrm{R} \$ 0\end{array}$ & $\begin{array}{c}25 \% \text { de chance de ganhar } \mathrm{R} \$ \\
3.000 ; 75 \% \text { de chance de } \\
\text { ganhar } \mathrm{R} \$ 0\end{array}$ & Total \\
\hline & & & $A$ & $B$ & \\
\hline Problema & $\begin{array}{c}20 \% \text { de chance } \\
\text { de perder } \mathrm{R} \$ \\
4.000 ; 80 \% \text { de } \\
\text { chance de } \\
\text { perder } \mathrm{R} \$ 0\end{array}$ & A & $7,6 \%$ & $26,6 \%$ & $34,2 \%$ \\
\hline 10 & $\begin{array}{c}25 \% \text { de chance } \\
\text { de perder } \mathrm{R} \$ \\
3.000 ; 75 \% \text { de } \\
\text { chance de } \\
\text { perder } \mathrm{R} \$ 0\end{array}$ & B & $10,1 \%$ & $55,7 \%$ & $65,8 \%$ \\
\hline & Total & & $17,7 \%$ & $82,3 \%$ & $100,0 \%$ \\
\hline
\end{tabular}

Fonte: pesquisa de campo (2019).

Tabela 06 - Problemas 11 e 12.

\begin{tabular}{cccc} 
Problema & Opção & Prospecto & Pesquisados \\
\hline 11 & A & $45 \%$ de chance de perder $\mathrm{R} \$ 6.000 ; 55 \%$ de chance de perder $\mathrm{R} \$ 0$ & $50,62 \%$ \\
& B & $90 \%$ de chance de perder $\mathrm{R} \$ 3.000 ; 10 \%$ de chance de perder $\mathrm{R} \$ 0$ & $49,38 \%$ \\
12 & A & $0,1 \%$ de chance de perder $\mathrm{R} \$ 6.000 ; 99,9 \%$ de chance de perder $\mathrm{R} \$ 0$ & $42,17 \%$ \\
& B & $0,2 \%$ de chance de perder $\mathrm{R} \$ 3.000 ; 99,8 \%$ de chance de perder $\mathrm{R} \$ 0$ & $57,83 \%$
\end{tabular}

Fonte: pesquisa de campo (2019).

No problema 12, as situações apresentadas possuem probabilidades muito baixas de perder e probabilidades muito altas de evitar a perda. A maioria dos respondentes preferiu a opção "B", a qual possui maior probabilidade de perda, mas com o valor menor. Estes respondentes tiveram aversão ao risco e não há perda. Ainda é possível observar um percentual relevante $(42,17 \%)$ daqueles que escolheram a opção " $A$ ". Assim, optantes pela opção " $A$ " são avessos a perdas e não ao risco, pois escolheram mais probabilidade de evitar a perda, mesmo sabendo que poderiam perder um valor $100 \%$ maior do que " $B$ ". A equação da utilidade pode ser descrita da seguinte forma: 0,001 x (-6000)<0,002 x (-3000).

Na relação do problema 11 com o problema 12, a maioria dos respondentes escolheram alternativas diferentes entre as questões, sendo " $A$ " e " $B$ ", respectivamente. Enquanto no problema 12, a maioria dos respondentes optou pela alternativa que ofereceu maior probabilidade de perda, mas com o valor menor, no 
problema 11, a maioria dos respondentes optou pela menor probabilidade de perder, mas caso percam, seria um valor maior. Tal resultado demonstram um desvio da utilidade no processo decisório dos respondentes.

O problema 11 é semelhante ao problema 07, sendo a única diferença os efeitos positivos e negativos. De acordo com o quadro $03,42 \%$ dos respondentes permaneceram com a mesma alternativa e 40,7\% escolheram alternativas diferentes ao deslocar o efeito positivo para negativo. Na situação de ganho (problema 07), a maioria dos respondentes optou pela alternativa que ofereceu maior probabilidade de ganho, mesmo com o valor menor, enquanto na situação de perda (problema 11) não se pode afirmar uma preferência clara entre as alternativas, mas é percebido que aqueles que optaram pela alternativa que ofereceu maior chance de evitar a perda, mesmo sabendo que poderia perder o dobro do valor da opção "B", são avessos às perdas e não aos riscos.

Quadro 03 - Relação do problema 07 e 11

\begin{tabular}{|c|c|c|c|c|c|}
\hline & & & Proble & & \\
\hline & & & $\begin{array}{c}\text { 45\% de chance de ganhar } \mathrm{R} \$ \\
6.000 ; 55 \% \text { de chance de } \\
\text { ganhar } \mathrm{R} \$ 0\end{array}$ & $\begin{array}{c}\text { 90\% de chance de ganhar } \\
\mathrm{R} \$ 3.00010 \% \text { de chance } \\
\text { de ganhar } \mathrm{R} \$ 0\end{array}$ & Total \\
\hline & & & A & $B$ & \\
\hline Problema & $\begin{array}{c}\text { 45\% de chance de } \\
\text { perder } \mathrm{R} \$ 6.000 ; 55 \% \\
\text { de chance de perder } \\
\mathrm{R} \$ 0\end{array}$ & A & $9,9 \%$ & $40,7 \%$ & $50,6 \%$ \\
\hline 11 & $\begin{array}{c}90 \% \text { de chance de } \\
\text { perder } \mathrm{R} \$ 3.000 ; 10 \% \\
\text { de chance de perder } \\
\mathrm{R} \$ 0\end{array}$ & B & $7,4 \%$ & $42,0 \%$ & $49,4 \%$ \\
\hline & Total & & $17,3 \%$ & $82,7 \%$ & $100,0 \%$ \\
\hline
\end{tabular}

Fonte: pesquisa de campo (2019).

O problema 12 é semelhante ao problema 08, apenas alterando os efeitos positivos e negativos. Nestes problemas, houve diferenças de respostas entre as opções, sendo " $B$ " e " $A$ ", respectivamente. Tais diferenças caracterizam o efeito reflexão, uma vez que no problema 12, os respondentes foram avessos aos riscos, enquanto no problema 08 aderiram ao risco para obter um valor maior.

Apesar das escolhas entre as opções terem sido diferentes entre a maioria dos respondentes do problema 12 e 08 (quadro 04), as maiores porcentagens (31,3\%) mostram que não houve deslocamento de preferências da opção " $A$ " para " $B$ " e vice-versa. No entanto, é percebido a frequência de $26,5 \%$ dos respondentes que escolheram alternativas distintas entre os problemas e influenciaram o resultado. 
Quadro 04 - Relação do problema 08 e 12

\begin{tabular}{|c|c|c|c|c|c|}
\hline & \multicolumn{2}{|c|}{ Questão 08} & \multirow{3}{*}{ Total } \\
\hline & & & $\begin{array}{l}0,1 \% \text { de chance de ganhar } \mathrm{R} \$ \\
6.000 ; 99,9 \% \text { de chance de } \\
\text { ganhar } \mathrm{R} \$ 0\end{array}$ & $\begin{array}{l}0,2 \% \text { de chance de } \\
\text { ganhar } \mathrm{R} \$ 3.000 ; 99,8 \% \\
\text { de chance de ganhar } \mathrm{R} \$ \\
0\end{array}$ & \\
\hline & & & $A$ & $B$ & \\
\hline \multirow{2}{*}{$\begin{array}{c}\text { Questão } \\
12\end{array}$} & $\begin{array}{l}0,1 \% \text { de chance de } \\
\text { perder } \mathrm{R} \$ 6.000 ; 99,9 \% \\
\text { de chance de perder } \\
\mathrm{R} \$ 0\end{array}$ & A & $31,3 \%$ & $10,8 \%$ & $42,2 \%$ \\
\hline & $\begin{array}{l}0,2 \% \text { de chance de } \\
\text { perder } \mathrm{R} \$ 3.000 ; 99,8 \% \\
\text { de chance de perder } \\
\mathrm{R} \$ 0\end{array}$ & B & $26,5 \%$ & $31,3 \%$ & $57,8 \%$ \\
\hline \multicolumn{2}{|r|}{ Total } & & $57,8 \%$ & $42,2 \%$ & $100,0 \%$ \\
\hline
\end{tabular}

Fonte: pesquisa de campo (2019).

\subsection{Efeito Isolamento}

No problema 13 (quadro 05), Tversky e Kahneman (1979) propuseram um produto hipotético, denominado "Seguro Probabilístico". A partir dos dados, percebe-se a negativa dos respondes em ambas as pesquisas para a atratividade de adquirir tal produto. Tversky e Kahneman (1979) afirmam que as pessoas costumam simplificar o processo decisório e por muitas vezes acabam tomando decisões equivocadas, uma vez que ignoraram elementos idênticos e destacam os elementos que os distinguem. Para a presente pesquisa, os resultados do problema 13 mostram uma violação da aversão ao risco, pois faz a atratividade de diminuir a probabilidade de uma perda $Z$ para metade de $Z(0,5 \times Z)$ ser inferior a atratividade de diminuir a probabilidade de $50 \%$ Z para 0 , isto é, ficar sem seguro.

\section{Quadro 05 - Problema 13}

Suponha que você esteja pensando na possibilidade de segurar um imóvel contra algum dano, por exemplo, incêndio ou roubo. Depois de examinar os riscos e o prêmio do seguro, você não encontra uma clara preferência entre a opção de adquirir o seguro e a opção de deixar o imóvel sem seguro. No entanto, chama-lhe a atenção que a seguradora está oferecendo um novo produto chamado Seguro Probabilístico. Neste novo produto, você paga inicialmente metade do prêmio de um seguro tradicional. No caso de dano, existe uma probabilidade de $50 \%$ de que você pague a outra metade do prêmio e que a seguradora cubra todas as perdas. Existe também a probabilidade de $50 \%$ de que, no caso de dano, você receba o valor já pago pelo prêmio e não seja ressarcido pelas perdas. Por exemplo, e o acidente ocorre em um dia ímpar, você paga a outra metade do prêmio e tem as perdas ressarcidas. Caso o acidente ocorra em um dia par, então a seguradora devolve o prêmio, os $50 \%$ já pagos inicialmente, e as perdas não são cobertas. Lembre-se de que o prêmio do seguro tradicional é tal que você avalia que o seguro praticamente equivale ao seu custo. Sob estas circunstâncias, você compraria o Seguro Probabilístico?

\begin{tabular}{|c|c|c|c|}
\hline Problema & Opção & Prospecto & Pesquisados \\
\hline \multirow{2}{*}{13} & A & Sim & $28,20 \%$ \\
\cline { 2 - 4 } & B & Não & $71,80 \%$ \\
\hline
\end{tabular}

Fonte: pesquisa de campo (2019). 
Segundo Tversky e Kahneman (1979), o Seguro Probabilístico é melhor que o Seguro Tradicional. No modo tradicional, o respondente deveria pagar Z como prêmio para evitar uma perda no valor $X$, que pode ocorrer com uma probabilidade indefinida (y). No Seguro probabilístico, o indivíduo poderia pagar um prêmio reduzido (cZ) e teria a probabilidade de perder $\mathrm{X}$ reduzida de y para (1-c) $\mathrm{y}$, com $1<\mathrm{c}<1$.

No problema 14 (quadro 06), a maioria dos respondentes optou pela opção "B", a qual oferece certeza de ganho e que atende ao efeito certeza. É possível observar que existe apenas $25 \%$ de ir para a segunda fase do jogo, o que altera a equação da utilidade para: 0,25 x 0,8 x U (4000) <0,25 x 1 x U (3000). A simplificação de tal equação se dá por 0,2 x U (4000) <0,25 x (3000).

\section{Quadro 06 - Relação do problema 14 e 04}

\begin{tabular}{|c|c|c|c|}
\hline \multicolumn{4}{|c|}{$\begin{array}{l}\text { Considere um jogo de dois estágios. No primeiro estágio existe uma probabilidade de } 75 \% \text { de que o jogo termine sem } \\
\text { que você ganhe nada e uma probabilidade de } 25 \% \text { de que se mova para o segundo estágio. Se você atingir o segundo } \\
\text { estágio, você pode escolher entre as alternativas a seguir. Observe que a escolha deve ser feita antes do início do jogo }\end{array}$} \\
\hline Problema & Opção & Prospecto & Pesquisados \\
\hline \multirow{2}{*}{14} & A & $80 \%$ de chance de ganhar $\mathrm{R} \$ 4.000 ; 20 \%$ de chance de ganhar $\mathrm{R} \$ 0$ & $15,19 \%$ \\
\hline & B & $100 \%$ de chance de ganhar $\mathrm{R} \$ 3.000$ & $84,81 \%$ \\
\hline \multirow{2}{*}{4} & A & $20 \%$ de chance de ganhar $\mathrm{R} \$ 4.000 ; 80 \%$ de chance de ganhar $\mathrm{R} \$ 0$ & $16,50 \%$ \\
\hline & B & $25 \%$ de chance de ganhar $\mathrm{R} \$ 3.000 ; 75 \%$ de chance de ganhar $\mathrm{R} \$ 0$ & $83,50 \%$ \\
\hline
\end{tabular}

Fonte: pesquisa de campo (2019).

A partir da simplificação, a equação da utilidade do problema 14 é idêntica ao problema 04, $(0,20 \times$ $\mathrm{U}(4.000)<0,25 \times \mathrm{U}(3.000)$ ). Tversky e Kahneman (1979) encontraram respostas diferentes nos problemas $14 \mathrm{e}$ 04, sendo "A" $\mathrm{e}$ " $B$ ", respectivamente. Assim, os autores levantaram a hipótese de que os indivíduos iriam apresentar respostas diferentes ao lidarem com o mesmo problema, só que reformulado. No entanto, esse comportamento não aconteceu neste estudo, pois mesmo que tenha inserido uma probabilidade de $25 \%$ de ir para a segunda etapa, os respondentes permaneceram com a opção "B" entre os problemas 04 e 14 , descartando assim, o efeito isolamento.

No problema 15 (quadro 07), a maioria dos respondentes optou pela opção "B", a qual oferece certeza de ganhar, porém como um valor menor - efeito certeza. Por outro lado, o problema 16 (quadro 07) não mostra uma preferência consistente entre os indivíduos para as opções " $A$ " ou " $B$ ". É possível observar que 49,40\% dos respondentes foram avessos às perdas e não aos riscos (efeito reflexão), mesmo com a possibilidade de perder um valor ainda maior.

Quadro 07 - Problema 15 e 16.

\begin{tabular}{|c|c|c|c|}
\hline \multirow{2}{*}{$\begin{array}{c}\text { Problema } \\
15\end{array}$} & \multicolumn{3}{|c|}{$\begin{array}{c}\text { Além dos recursos que você possui, você recebeu mais R\$ 1.000. Agora, você deve escolher } \\
\text { entre as alternativas a seguir: }\end{array}$} \\
\cline { 2 - 4 } & Opção & \multicolumn{1}{|c|}{ Prospecto } & Pesquisados \\
\cline { 2 - 4 } & A & $\begin{array}{l}50 \% \text { de chance de ganhar R\$ 1.000; 50\% de chance de ganhar } \\
\text { R\$ 0 }\end{array}$ & $21,69 \%$ \\
\hline
\end{tabular}




\begin{tabular}{|c|c|c|c|}
\hline \multirow{4}{*}{$\begin{array}{l}\text { Problema } \\
16\end{array}$} & \multicolumn{3}{|c|}{$\begin{array}{c}\text { Além dos recursos que você possui, você recebeu mais } \mathrm{R} \$ 2.000 \text {. Agora, você deve escolher } \\
\text { entre as alternativas a seguir: }\end{array}$} \\
\hline & Opção & Prospecto & Pesquisados \\
\hline & A & $\begin{array}{l}50 \% \text { de chance de perder } \mathrm{R} \$ 1.000 ; 50 \% \text { de chance de perder } \mathrm{R} \$ \\
0\end{array}$ & $49,40 \%$ \\
\hline & B & $100 \%$ de chance de perder $\mathrm{R} \$ 500$ & $50,60 \%$ \\
\hline
\end{tabular}

Fonte: pesquisa de campo (2019).

Os problemas 15 e 16 são iguais, pois $1000+(1000: 50 \% ; 500: 100 \%)=2000+(-1000: 50 \% ;-500: 100 \%)$. De acordo com Kimura e Basso (2003), a soma de R\$1.000 ao valor inicial e a diminuição de $\mathrm{R} \$ 1.000$ dos prospectos faz com que os indivíduos ignorem as informações semelhantes e foquem apenas no ganho certo do problema 15 (opção B) e possibilidade de evitar a perda no problema 16 (problema A). A reformulação do problema fez com que $49,40 \%$ dos respondentes optassem por respostas diferentes entre as questões, mas caso a análise seja realizada pela maioria simples, não houve desvios no processo decisório.

\section{CONSIDERAÇÕES FINAIS}

Este estudo teve como objetivo replicar o estudo clássico sobre Finanças Comportamentais, através da metodologia proposta por Tversky e Kahneman (1979), em investidores imobiliários que atuam com locação de imóveis na cidade de Vitória da Conquista - BA.

O efeito certeza foi apresentado pela maioria dos respondentes em sete das oito questões analisadas para esse efeito. Quatro questões das oito ofereciam diferenças de até $5 \%$ entre as alternativas e com retornos diferentes, mas o único problema que não apresentou o efeito certeza, ofereceu baixíssimas probabilidade de ganho $(0,01 \%$ e $0,02 \%)$, mas com diferenças significativas de retornos. Assim, para este problema, os respondentes optaram por retornos maiores.

O efeito reflexão foi constatado pela maioria dos respondentes em duas das quatro questões analisadas. Ao alterar os efeitos positivos para negativos, uma parcela dos respondentes assumiu os riscos para evitar perdas, sendo que antes foram avessos nas situações de ganhos. Vale ressaltar que um dos problemas que não apresentou o efeito reflexão, também não apresentou diferenças significativas entre as escolhas das alternativas, sendo que estas opções tinham diferenças de até $5 \%$ para evitar a perda. Como as diferenças eram pouco significativas, os respondentes que não apresentaram o efeito reflexão optaram pela maior chance de perda, mas com valor a perder reduzido.

Há evidências do efeito isolamento em dois dos três casos apresentados. O problema 16 não apresentou uma preferência significativa entre os problemas, mas $49,4 \%$ dos respondentes desta questão foram enviesados pelo efeito isolamento, ao escolherem respostas diferentes para o mesmo problema. Dessa forma, a simplificação da análise, fez com que uma parcela dos respondentes ignorasse informações relevantes e mantivesse apenas as informações que consideraram necessárias, levando a inconsistências quando o problema foi reformulado. A simplificação pode levar a uma inconsistência no processo decisório.

O perfil do investidor imobiliário nesta pesquisa apresentou, na situação de ganho, ser majoritariamente avesso aos ricos, mesmo com pequenas diferenças de probabilidades entre as alternativas, exceto se ambas alternativas apresentarem baixíssimas probabilidades de ganhos. Ao trocar as situações de positivo para negativo (efeito reflexão), uma parcela dos respondentes passou de aversão aos riscos para adeptos destes, a fim de evitar uma perda, mesmo sabendo que poderia perder um valor maior. No efeito isolamento, a maioria dos respondentes simplificou a análise para a tomada de decisão e que levou a escolha por respostas diferentes para os mesmos problemas.

Dessa forma, os investidores imobiliários que atuam com aluguel em Vitória da Conquista apresentam características de um processo decisório inconsistente em situações que envolvam probabilidades de ganhos 
ou perdas, sendo susceptíveis aos efeitos certeza, reflexão e isolamento. Para futuras pesquisas, sugere-se a análise dos problemas apresentados por Tversky e Kahnemam (1979) correlacionados com as percepções de riscos e retornos do investidor imobiliário a respeito de suas aplicações em imóveis para aluguel. Apesar das limitações inerentes à pesquisa, esta pode servir de base para pesquisadores que queiram dar continuidade as investigações sobre o processo decisório dos investidores, de modo a trazer contribuições significativas para a academia, para o mercado e para a sociedade.

\section{REFERÊNCIAS}

BALDO, Dinorá. Biomarcas nas anomalias da teoria da utilidade esperada. 2007. 89f. Dissertação (Mestrado em Economia) - Universidade Federal de Santa Catarina, Florianópolis, 2007.

BARROS, Thiago de Sousa; FELIPE, Israel José dos Santos; Teoria do prospecto: evidências aplicadas em Finanças Comportamentais. Revista de Administração FACES Journal, Belo Horizonte, v. 14, n. 4, p. 75-95, 2015.

BILK, Ângela et al. Aversão a Perda e Satisfação ao Ganho nos Aspectos Comportamentais dos Acadêmicos e Profissionais da Atuária. Caderno Profissional de Administração - UNIMEP, São Paulo, v. 8, n. 1, p. 25-44, 2018.

FAGUNDES, Ernando, SCHNORREMBERGER Darci, LUNKES, Rogério João. AVERSÃO AO RISCO NA TOMADA DE DECISÕES ORGANIZACIONAIS: ANÁLISE DA LITERATURA E OPORTUNIDADES DE PESQUISA. Revista de Contabilidade do Mestrado em Ciências Contábeis da UERJ (online), Rio de Janeiro, v. 23, n. 2, p. 19-36, 2018.

FAMA, Eugene Francis. Efficient Capital Markets: A Review of Theory and Empirical Work. The Journal of Finance, New York. v. 25, n. 2, p. 383-417, 1970. Disponível em:

https://www.jstor.org/stable/2325486?seq=1\#page_scan_tab_contents. Acesso em: 06 jan. 2019.

FERNANDES, Gustavo dos Santos et al. Finanças Comportamentais: um estudo comparativo utilizando a teoria dos prospectos com os alunos de graduação e pós-graduação de uma IES. In: CONGRESSO INTERNACIONAL DE ADMINISTRAÇÃO, 29., 2016, Natal. Anais [...]. Natal: FASF, 2016.

FRIES, Laina de Oliveira. Teoria da utilidade esperada e hipótese do mercado eficiente na perspectiva da economia comportamental. 2017. 55f. Dissertação (Graduação em Ciências Econômicas) - Universidade Federal de Santa Catarina, Florianópolis - SC, 2017.

KIMURA, Herbert; BASSO, Leonardo Fernando Cruz. Finanças comportamentais: investigação do comportamento decisório dos agentes brasileiros. In: ENCONTRO NACIONAL DAS ASSOCIAÇÕES DOS PROGRAMAS DE PÓS-GRADUAÇÃO EM ADMINISTRAÇÃO (EnANPAD), 27., 2003., São Paulo. Atas do XXVII EnANPAD. São Paulo: ANPAD, 2014.

LOBEL, Robert Eugene; KLOTZLE, Marcelo Cabus; SILVA, Paulo Vitor Jordão da Gama. Prospect theory: a parametric analysis of functional forms in Brazil. RAE-Revista de Administração de Empresas, v. 57, n. 5, p. 495-509, 2017.

MACEDO, Jurandir Sell Jr et al. Os fatores genéticos explicando os traços da psicologia e do comportamento humano e sua influência para as Finanças Comportamentais. In: CONGRESSO UFSC DE CONTROLADORIA E FINANÇAS, 1., 2007, Florianópolis, SC. Anais do I Congresso UFSC de Controladoria e Finanças.

Florianópolis: UFSC, 2007.

MARTINS, Orleans Silva; LIMA, Diana Vaz de; SILVA, José Dionísio Gomes da. Frame Dependence no comportamento do profissional contábil face à adoção dos novos padrões contábeis internacionais. Enfoque.: Reflexão Contábeis, Paraná, v. 34 n. 2 p. 51-69, 2015. 
OLIVEIRA, Rossimar Laura; KRAUTER, Elizabeth. Teoria do prospecto: como as finanças comportamentais podem explicar a tomada de decisão. Pretexto, Belo Horizonte v. 16, n. 3, p. 106-121, 2015.

PRODANOV, Cleber Cristiano; FREITAS, Ernani Cesar. Metodologia do Trabalho Científico: métodos e técnicas da pesquisa e do trabalho acadêmico. 2. ed. Novo Hamburgo: Feevale, 2013.

ROSA, Iriane Rodrigues da; MILANI, Bruno. Aversão ao Risco Financeiro: Um Estudo Sobre o Comportamento de Estudantes de Nível Superior. Caderno Profissional de Administração da UNIMEP, v. 5, n. 2, p. 84-102, 2015.

SHLEIFER, Andrei. Inefficient Markets: an introduction to Behavioral Finance. Oxford: Ed. Oxford University Press, 2000.

SILVA FILHO, Darlan Maciel. Finanças Comportamentais: o comportamento do agente decisório nos cenários de ganhos, perdas, riscos e incertezas. 2011. 107 f. Dissertação (Mestrado em Economia) Universidade Estadual Paulista Júlio de Mesquita Filho, Araraquara - São Paulo, 2011

TRIVIÑOS, Augusto Nibaldo Silva. Introdução à pesquisa em ciências sociais: a pesquisa qualitativa em educação. São Paulo: Atlas, 2009.

TVERSKY, Amos; KAHNEMAN, Daniel. Prospect Theory: An Analysis of Decision under Risk. Econometrica, $v$. 47, n. 2, p. 263-292, 1979.Disponível em: https://www.jstor.org/stable/1914185 . Acesso em: 06 jan. 2019

YOSHINAGA, C. E.; RAMALHO, T. B. Finanças Comportamentais no Brasil: uma aplicação da teoria da perspectiva em potenciais investidores. Revista Brasileira de Gestão de Negócios, v. 16, n. 53, p. 594-615, 2014. 